\title{
Papers
}

\section{Stressful life experiences and risk of relapse of breast cancer: observational cohort study}

\author{
Jill Graham, Amanda Ramirez, Sharon Love, Michael Richards, Caroline Burgess
}

\begin{abstract}
Objective To confirm, using an observational cohort design, the relation between severely stressful life experiences and relapse of breast cancer found in a previous case-control study.

Design Prospective follow up for five years of a cohort of women newly diagnosed as having breast cancer, collecting data on stressful life experiences, depression, and biological prognostic factors. Setting NHS breast clinic, London; 1991-9. Participants A consecutive series of women aged under 60 newly diagnosed as having a primary operable breast tumour. 202/222 (91\%) eligible women participated in the first life experiences interview. $170(77 \%)$ provided complete interview data either up to 5 years after diagnosis or to recurrence. Main outcome measure Recurrence of disease. Results We controlled for biological prognostic factors (lymph node infiltration and tumour histology), and found no increased risk of recurrence in women who had had one or more severely stressful life experiences in the year before diagnosis compared with women who did not (hazard ratio $1.01,95 \%$ confidence interval 0.58 to $1.74, \mathrm{P}=0.99$ ). Women who had had one or more severely stressful life experiences in the 5 years after diagnosis had a lower risk of recurrence $(0.52,0.29$ to $0.95, \mathrm{P}=0.03)$ than those who did not.

Conclusion These data do not confirm an earlier finding from a case-control study that severely stressful life experiences increase the risk of recurrence of breast cancer. Differences in case control and prospective methods may explain the contradictory results. We took the prospective study as the more robust, and the results suggest that women with breast cancer need not fear that stressful experiences will precipitate the return of their disease.
\end{abstract}

\section{Introduction}

Chronic stress is associated with an increased risk of developing symptoms of heart disease ${ }^{1}$ and, for some individuals, stressful events in life trigger depression. ${ }^{2}$ The role of psychosocial factors in the onset and progression of cancer is less clear. The relation between stressful life experiences and onset of breast cancer has been the subject of a great deal of research, much of which has been characterised by weak design. A recent meta-analysis concluded that the few well designed studies that have been carried out failed to find evidence of a link. ${ }^{3}$

Fewer studies have examined the association between stress and the recurrence of breast cancer. Between a quarter and a third of women diagnosed with operable breast cancer will have a recurrence of their disease within five years of it being diagnosed. Several biological factors, such as axillary lymph node involvement and histological grade, are known to influence breast cancer prognosis, yet women with apparently similar tumours at the time of presentation differ markedly in their disease-free survival and overall survival. This raises the possibility that such differences in outcome may be explained by host and environmental factors, which could include psychological and social variables. A mechanism by which stressful life experiences could influence recurrence of disease has been identified by preliminary immunological data. These data indicate that downregulation of the immune system occurs, via reduced activity of natural killer cells, after exposure to a variety of environmental stressors. ${ }^{4}$ Furthermore, some data suggest that psychological interventions can improve survival for women with metastatic breast cancer, ${ }^{56}$ although a relation has yet to be shown conclusively. ${ }^{7}$

Studies that have investigated the relation between stressful life experiences and cancer progression provide conflicting data. Three out of five case-control studies found an increased risk of recurrence among women with stressful life experiences ${ }^{8-10}$ whereas two found no increased risk. ${ }^{11}{ }^{12}$ All the studies are subject to methodological weaknesses involving one or more measurements of stressful life experiences, selection of study sample, and matching of cases and controls. The single population based study to be carried out to date failed to find any increased risk of recurrence or death among over 14000 women with cancer who had lost either a spouse or a child. ${ }^{13}{ }^{14}$

One study has examined the association between stressful life experiences occurring in the postoperative period and subsequent recurrence. ${ }^{15}$ It found no association, but this may have resulted from methodological factors, including limited control of biological prognostic factors, an insufficiently long follow up period, and a lack of power. Re-analysis after a longer period again found no association. ${ }^{16}$ From examining studies carried out to date it is clear that the question of
Cancer Research
UK London
Psychosocial Group,
Adamson Centre,
Guy's, King's and
St Thomas's School
of Medicine,
St Thomas's
Hospital, London
SE1 7EH
Jill Graham
health psychologist
Amanda Ramirez
professor of liaison
psychiatry
Michael Richards
Sainsbury professor of
palliative medicine
Caroline Burgess
health psychologist
Cancer Research
UK Medical
Statistics Group,
Centre for Statistics
in Medicine,
Institute of Health
Sciences, Oxford
OX3 7LF
Sharon Love
medical statistician
Correspondence to:
J Graham
jill.graham@kcl.ac.uk
bmj.com 2002;324:1420 
whether stressful life experiences influence disease recurrence remains unanswered.

The aims of this study were to investigate the relation between stressful life experiences and relapse of breast cancer in a methodologically robust way. We collected data on stressful life experiences prospectively by using a standardised, interview based instrument; we controlled for the main biological factors known to influence prognosis of breast cancer; and we used a relatively long follow up period.

\section{Participants and methods}

\section{Participants}

We approached a consecutive series of 222 women who had been diagnosed with a primary operable breast tumour at Guy's Hospital between May 1991 and July 1994. We excluded women at low risk of recurrence (women with a very small tumour $(<1 \mathrm{~cm})$ and no lymph node involvement) and women older than 60 years, because older women have relatively fewer stressful life experiences than younger women. ${ }^{17}$

\section{Methods}

We collected data from the women on stressful life experiences and depression. Interviews, which were tape recorded and transcribed, were carried out every 18 months and covered the period from 12 months before diagnosis to five years after diagnosis. We identified details of the timing and nature of any recurrence through weekly examination of the breast unit's database and follow up records made by the clinic. We took the date of recurrence as the date of onset of a physical sign that was confirmed radiologically or histologically as a recurrence. ${ }^{18}$ Our final interview with patients who had a recurrence took place approximately eight weeks after the diagnosis.

\section{Instruments}

We collected data on stressful life experiences by using the Bedford College life events and difficulties schedule. ${ }^{17}$ This is a semi-structured standardised interview that inquires about discrete life events and more longstanding difficulties. Each stressful life experience is given a severity rating, reflecting the degree to which it would be threatening to a hypothetical woman in the same life circumstances. Using this approach rather than the participant's subjective description of the threat associated with the experience reduces the bias that could arise from the participant's report of life experiences. An example of a severe event is divorce, whereas a severe difficulty could be caring for a severely handicapped child. To test inter-rater reliability two interviewers independently rated interviews from a random sample of 10 women. Agreement was good for life events (agreement $92 \%$, weighted $x$ coefficient 0.75 ) and moderate for difficulties $(91 \%, 0.63)$.

At each interview we elicited psychiatric symptoms by using the structured clinical interview using criteria from the Diagnostic and Statistical Manual of Mental Disorders (third edition, revised), to enable us to identify episodes of persistent depression (lasting three months or longer) experienced by the women. ${ }^{19}$ We obtained data on biological prognostic factors (tumour size, tumour histology, number of axillary nodes with tumour infiltration) from the clinical database at the Guy's oncology unit.

\section{Statistical aspects}

Because severely stressful life experiences and episodes of depression could occur at any time over the study period, the analysis used Cox proportional hazards model with time dependent covariates. ${ }^{20}$ This gave an estimate of the effect of each risk factor in the form of a hazard ratio. Multivariate analysis enabled adjustment for known prognostic factors such as nodal infiltration, which we identified as prognostic for this sample univariately, using the log rank test. ${ }^{21}$ With 200 participants and an expected 50 recurrences, there was $80 \%$ power to find 2.2 times the risk of relapse significant at $\mathrm{P}=0.05$.

\section{Results}

Of $202(91 \%)$ women who completed an initial interview, 171 (77\% of the original 222 eligible) provided complete interview data either up to five years after diagnosis or to recurrence. Patients with incomplete data were included in the analysis to preserve the consecutive series. Some patients died soon after recurrence, therefore four of the final interviews after recurrence were completed by the woman's closest relative.

The overall five year relapse-free survival was $76 \%$ (95\% confidence interval 68.6 to 81.1). Recurrence of disease was confirmed in 54 women. Disease factors were worse for women who subsequently had a recurrence; sociodemographic factors were similar in the two groups (table 1). Rates of severe life events and difficulties, and episodes of persistent depression are shown in table 2. Examination of the number of events by month indicated that there was no fall off in the reporting of severe events as the time between the event and the interview increased. This suggests that women did not forget severe events that had occurred long before the interview took place.

\section{Associations between life experiences and recurrence}

After the effects of lymph node infiltration and histological type were adjusted for, women who had one or more severely stressful life experiences in the year before diagnosis did not have an increased risk of recurrence compared with women without such experiences (table 3). Likewise, an episode of depression before diagnosis did not increase the risk of recurrence (hazard ratio $1.22,0.38$ to $3.92, \mathrm{P}=0.7$ ).

In the post-diagnosis period, after adjustment for nodes and histological type, women who had one or more severely stressful life experiences had a lower risk of recurrence than those who did not (table 3). Separate examination of life events and difficulties indicated that the effect was primarily caused by events (yes $v$ no, $0.54,0.30$ to $0.96, \mathrm{P}=0.04$ ) rather than difficulties (yes $v$ no, $0.79,0.44$ to $1.4, \mathrm{P}=0.4$ ). Having an episode of depression did not increase the risk of recurrence $(0.88,0.42$ to $1.87, \mathrm{P}=0.7)$.

\section{Discussion}

This study found no evidence that women who have a severely stressful life experience in the year before 
being diagnosed with breast cancer, or in the five years afterwards, are at any increased risk of developing a recurrence of their disease. In fact, women who had one or more severely stressful life experiences after diagnosis had a lower risk of recurrence than those who did not. It is perhaps a marginal association, with the upper limit of the $95 \%$ confidence interval close to 1. However, the only other study to use such detailed assessment of stressful life experiences reported a reduced risk of recurrence among women who had one or more severely stressful life experiences in the 12 months before surgery. ${ }^{15}$ These intriguing findings are in the opposite direction to the outcome hypothesised, and it is difficult to formulate a rationale to explain how stressful life experiences might reduce a woman's chance of experiencing a recurrence of her disease.

\section{Validity of the data}

The data in this study were collected from a sufficiently large sample of women to enable identification of a doubling of the risk of recurrence after a severe life experience-a conservative estimate based on previous findings. ${ }^{10}$ The follow up period was longer than that in the only other similar prospective study, ${ }^{15}$ so, if stressful life experiences cause recurrence only after a latent period, the longer follow up would have increased the likelihood of an association being detected. The present study used a thorough measure of stressful life experiences, using a semi-structured interview to obtain details of experiences and a method of assessing the degree of threat posed by experiences, which takes into account the context in which they occur. The study used a prospective design, which meant that for most of the data collection, participant and interviewer were blind as to whether the disease would recur. Only for the final interviews of women who had a recurrence was the outcome known, and this represented a small amount of the data. All of these factors would enhance the quality of the data and reduce the likelihood that the outcome is the result of bias.

\section{Comparison with other studies}

Of studies that have used a thorough assessment of stressful life experiences, studies with a prospective design (the current study, and that by Barraclough ${ }^{15}$ ) found no increase in the risk of recurrence of breast cancer, whereas the single case-control study found a strongly increased risk. ${ }^{10}$ Differences in case-control and prospective methods may explain the contradictory results arising from these two types of study.

Firstly, bias in recall of life events may have produced spurious associations in the case-control study. Women were asked to recall stressful life experiences over a long period of time (up to five years), and they were also aware that their disease had recurred. This may have encouraged a greater number of women with a recurrence to recall experiences as a way of seeking something to blame for the return of their disease. The prospective studies reduced recall bias by conducting interviews every 18 months and collecting data before women were aware of the recurrence of their cancer.

Secondly, spurious associations may have resulted from features of the sample in the case-control study. All women who were invited agreed to participate in the case-control study, which may imply an atypical sample. The sample was small, and the increased risk of
Table 1 Sociodemographic and disease characteristics of women with and without recurrence of breast cancer. Results are numbers (percentages) unless stated otherwise

\begin{tabular}{|c|c|c|c|c|}
\hline \multirow[b]{2}{*}{ Variable } & \multicolumn{2}{|c|}{ Recurrence } & \multirow[b]{2}{*}{ Log rank (df) } & \multirow[b]{2}{*}{$P$ value } \\
\hline & Yes $(n=54)$ & № $(n=148)$ & & \\
\hline \multicolumn{5}{|l|}{ Age (years): } \\
\hline Mean (SD) & $47.7(8.54)$ & $48.7(7.55)$ & & \\
\hline$\leqslant 49$ & $28(52)$ & $66(45)$ & \multirow{2}{*}{$1.6(1)$} & \multirow{2}{*}{0.2} \\
\hline$\geqslant 50$ & $26(48)$ & $82(55)$ & & \\
\hline \multicolumn{5}{|l|}{ Social class: } \\
\hline $\begin{array}{l}\text { Professional or } \\
\text { intermediate }\end{array}$ & $19(35)$ & 56 (38) & \multirow{2}{*}{$0.3(1)$} & \multirow{2}{*}{0.6} \\
\hline Other & $35(65)$ & $92(62)$ & & \\
\hline \multicolumn{5}{|l|}{ Marital status: } \\
\hline Single & $4(7)$ & $14(9)$ & \multirow{4}{*}{$1.5(3)$} & \multirow{4}{*}{0.6} \\
\hline Married or cohabiting & $42(78)$ & $109(74)$ & & \\
\hline Divorced or separated & $5(9)$ & $20(14)$ & & \\
\hline Widowed & $3(6)$ & $5(3)$ & & \\
\hline \multicolumn{5}{|c|}{ No of axillary nodes infiltrated with tumour: } \\
\hline None & $14(26)$ & $67(45)$ & \multirow{4}{*}{$10.6(3)$} & \multirow{4}{*}{$0.01 \dagger$} \\
\hline $1-3$ & $21(39)$ & $61(41)$ & & \\
\hline $4-9$ & $12(22)$ & 17 (12) & & \\
\hline$\geqslant 10$ & $7(13)$ & $3(2)$ & & \\
\hline \multicolumn{5}{|l|}{ Histology: } \\
\hline Ductal I & $0(0)$ & $28(19)$ & \multirow{6}{*}{$22.6(5)$} & \multirow{6}{*}{$0.0004 \dagger$} \\
\hline Ductal II & $13(24)$ & $40(27)$ & & \\
\hline Ductal III & $29(54)$ & $35(24)$ & & \\
\hline Lobular & $7(13)$ & 18 (12) & & \\
\hline Medullary/tubular/mucoid & $0(0)$ & $7(5)$ & & \\
\hline Other or ungraded & $5(9)$ & $20(13)$ & & \\
\hline \multicolumn{5}{|l|}{ Tumour size*: } \\
\hline$<2 \mathrm{~cm}$ & $20(37)$ & $74(50)$ & \multirow{3}{*}{$1.9(2)$} & \multirow{3}{*}{0.4} \\
\hline $2-5 \mathrm{~cm}$ & $27(50)$ & $60(40)$ & & \\
\hline$>5 \mathrm{~cm}$ & $5(10)$ & $10(7)$ & & \\
\hline \multicolumn{5}{|l|}{ Depression before diagnosis: } \\
\hline Yes & $3(6)$ & $10(7)$ & \multirow{2}{*}{$0.1(1)$} & \multirow{2}{*}{0.7} \\
\hline No & $51(94)$ & $138(93)$ & & \\
\hline \multicolumn{5}{|c|}{ Severe life event before diagnosis: } \\
\hline Yes & $25(46)$ & $65(44)$ & \multirow{2}{*}{$0.0(1)$} & \multirow{2}{*}{1.0} \\
\hline No & $29(54)$ & $83(56)$ & & \\
\hline
\end{tabular}

${ }^{*}$ No data for two patients with recurrence; four patients without recurrence.

$† P<0.05$ for the log rank test indicates that there is a significant difference in time to recurrence between women with different categories of the variable.

Table 2 Rates of severe life events, severe difficulties, and episodes of depression before and after diagnosis of breast cancer

\begin{tabular}{lcc} 
& $\begin{array}{c}\mathbf{1 2} \text { months before diagnosis } \\
(\mathbf{n}=\mathbf{2 0 2})\end{array}$ & $\begin{array}{c}\mathbf{5} \text { years after diagnosis } \\
(\mathbf{n}=\mathbf{2 0 2})\end{array}$ \\
\hline Severe events: & 57 & 131 \\
\hline No of women with one or more & 0.44 & 0.43 \\
\hline Annual rate & & 75 \\
\hline Severe difficulties: & 68 & 0.33 \\
\hline No of women with one or more & 0.45 & 55 \\
\hline Annual rate & 13 & \\
\hline $\begin{array}{l}\text { No of women with an episode of } \\
\text { depression lasting } 3 \text { months or more }\end{array}$ & & \\
\hline
\end{tabular}

Table 3 Effect of severely stressful life experiences on risk of recurrence of breast cancer* $^{*}$

\begin{tabular}{llc} 
& Hazard ratio $\mathbf{( 9 5 \%} \mathbf{C l})$ & P value \\
\hline Before diagnosis: & & \\
\hline Severe life experience $($ yes $v$ no) & $1.01(0.58$ to 1.74$)$ & 0.99 \\
\hline Nodes involved $(0,1-3,4-9, \geqslant 10)$ & $1.66(1.24$ to 2.22$)$ & 0.001 \\
\hline Histological type (ductal grade III $v$ other $)$ & $3.33(1.92$ to 5.79$)$ & $<0.001$ \\
\hline After diagnosis: & & \\
\hline Severe life experience (yes $v$ no) & $0.52(0.29$ to 0.95$)$ & 0.03 \\
\hline Nodes involved $(0,1-3,4-9, \geqslant 10)$ & $1.68(1.27$ to 2.22$)$ & $<0.001$ \\
\hline Histological type (ductal grade III $v$ other $)$ & $3.45(2.0$ to 5.96$)$ & $<0.001$ \\
\hline${ }^{*}$ Final Cox model. &
\end{tabular}




\section{What is already known on this topic}

Women with apparently similar tumours at the time of presentation with breast cancer differ considerably in their disease-free survival and overall survival

Such differences in outcome may well be explained by host and environmental factors, which could include psychological and social variables

Data on the relation between severely stressful life experiences and cancer progression have been contradictory

\section{What this study adds}

Women who have a severely stressful life experience in the year before being diagnosed with breast cancer, or in the five years afterwards, do not seem to be at increased risk of developing a recurrence of the disease

Women with breast cancer need not fear that stressful experiences will precipitate the return of their disease.

recurrence found was associated with a wide confidence interval. Overzealous matching may have resulted in case and control samples so similar that any small difference was exaggerated. ${ }^{22}$ A control sample so finely matched on biological factors may not be representative of women with breast cancer in general. The sample in the current prospective study is likely to be more representative of breast cancer patients because it was accrued as a consecutive series with an expected level of dropouts and refusers.

We took the prospective studies as the more robust, and these data indicate that women with breast cancer need not fear that stressful experiences in life are likely to bring about the return of their disease.

We thank Tirril Harris for invaluable advice on the life events and difficulties schedule, Professor Tom Craig for his input in designing the study, Karen Pinder for carrying out data collection interviews, and the participants for so generously talking about their lives.

Contributors: AR designed and set up the study and JG was responsible for its day to day management. SL provided statistical advice and undertook the data analysis. MR and CB provided input to the design, management, and analysis. All authors contributed to writing the paper. AR will act as guarantor for the paper.

Funding: Cancer Research UK.

Competing interests: None declared.

1 Karasek R, Theorell T. Healthy work: stress, productivity, and the reconstruction of working life. New York: Basic Books, 1990.

2 Brown G, Harris T. Life events and illness. London: Unwin Hyman, 1989.

3 Petticrew A, Fraser J, Regan M. Adverse life-events and risk of breast cancer: a meta analysis. Br J Health Psychol 1999;4:1-17.

4 Kiecolt-Glaser J, Glaser R. Psychoneuroimmunology and cancer: fact or fiction? Eur J Cancer 1999;35:1603-7.

5 Fawzy F, Fawzy N, Hyun C, Elashoff R, Guthrie D, Fahey J, et al. Effects of an early structured psychiatric intervention, coping, and affective state on recurrence and survival 6 years later. Arch Gen Psychiatry 1993;50:681-9.

6 Spiegel D, Bloom J, Kraemer H, Gottheil E. Effect of psychosocia treatment on survival of patients with metastatic breast cancer. Lancet 1989;ii:888-91.

7 Edelman S, Craig A, Kidman A. Can psychotherapy increase the survival time of cancer patients? J Psychosom Res 2000;49:149-56.

8 Forsen A. Psychosocial stress as a risk for breast cancer. Psychother Psychosom 1991;55:176-85.

9 Funch D, Marshall J. The role of stress, social support and age in survival from breast cancer. J Psychosom Res 1983;27:77-83.

10 Ramirez A, Craig T, Watson J, Fentiman I, North W, Rubens R. Stress and relapse of breast cancer. BMJ 1989;298:291-3.

11 Giraldi T, Rodani M, Cartei G, Grassi L. Psychosocial factors and breast cancer: a 6 year Italian follow-up study. Psychother Psychosom 1997;66:22936.

12 Maunsell E, Brisson M, Mondor R, Verreault R, Deschenes L. Stressful life events and survival after breast cancer. Psycho-Oncology 1998;7(4) (suppl):281.

13 Kvikstad A, Vatten L, Tretli S. Widowhood and divorce in relation to overall survival among middle-aged Norwegian women with cancer. $\mathrm{BrJ}$ Cancer 1995;71:1343-7.

14 Kvikstad A, Vatten L. Risk and prognosis of cancer in middle aged women who have experienced the death of a child. Int J Cancer 1996;67:165-9.

15 Barraclough J, Pinder P, Cruddas M, Osmond C, Taylor I, Perry M. Life events and breast cancer prognosis. BMJ 1992;304:1078-81.

16 Barraclough J, Osmond C, Taylor I, Perry M, Collins P. Life events and breast cancer prognosis. BMJ 1993;307:25

17 Brown G, Harris T. Social origins of depression: a study of psychiatric disorder in women. London: Tavistock, 1978.

18 Hayward J, Meakin W, Stewart H. Assessment of response and recurrence in breast cancer. Semin Oncol 1978;5:445-9.

19 Spitzer R, Williams J, Gibbon M, First M. Structured clinical interview for DSM III R-patient edition (SCID-P, version 1.0). Washington, DC: American Psychiatric Press, 1990.

20 Parmar M, Machin D. Survival analysis: a practical approach. Chichester: Wiley, 1995.

21 Peto R, Pike M, Armitage P, Breslow N, Cox D, Howard S, et al. Design and analysis of randomized clinical trials requiring prolonged observation on each patient II: analysis and examples. Br J Cancer 1977;35:1-39.

22 Breslow N, Day N. Statistical methods in cancer research. Lyon: International Agency for Research on Cancer, 1980.

(Accepted 19 December 2001) 